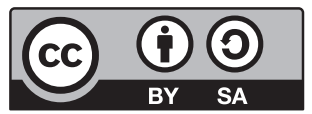

Seray Tanyer

Anadolu University, Turkey

Samet Deniz

Anadolu University, Turkey
iD https://orcid.org/0000-0001-6190-8651

iD https://orcid.org/0000-0002-4493-816X

\title{
Turkish EFL Learners' Acquisition of Psych Verbs and Unaccusative Verbs: \\ A Replication Study on Underpassivization and Overpassivization
}

\begin{abstract}
The processability account anticipates that learners will make more underpassivization errors than overpassivization errors since passivization entails more processing. Although one study on psych verbs and a few on unaccusatives examined Turkish L2 learners' acquisition, no research compared a single set of learners' acquisitions of these verbs together from a processing point of view. In this regard, the current study aims to investigate whether the processing complexity of passivization influences acquisition of psych and unaccusative verbs. It also questions whether general accuracy levels in Grammaticality Judgement Task (GJT) and degree of familiarity with target verbs are related to their level of accuracy with individual psych and unaccusative verbs. 33 undergraduate-level university students performed on the GJT and a Word Familiarity Rating Task (WFRT). The GJT included 38 items with 12 sentences for psych verbs, 12 sentences for unaccusative verbs, 12 sentences for distracters and two sentences for examples. The WFRT was a survey questioning familiarity with six psych and six unaccusative verbs. To analyse the data, a set of nonparametric tests and descriptive statistics were used. The results revealed that learners performed more accurately on unaccusatives than on psych verbs. They did more underpassivization errors by accepting ungrammatical active constructions of psych verbs. Their performances on psych and unaccusative verbs went parallel with their general accuracy levels in GJT while their degree of familiarity with and accuracy level for two verbs do not correlate with each other. The results suggest that such factors as processability and L1 transfer seem to impact the acquisition.
\end{abstract}

Keywords: second language acquisition, psych verbs, unaccusative verbs, underpassivization, overpassivization 
Research on L1 acquisition indicates that acquisition of passive voice by native English children is postponed to the later stages during their language development (de Villiers \& de Villiers, 1973). This later development of child language in terms of passivization has been attributed to the complexity of syntactic operations and problems in semantic-syntactic mapping (Pienemann, 2005). In a scenario where processability plays a role in the acquisition of English as an L2, passive constructions requiring more processing will be more difficult to acquire as compared to active constructions. As a result, L2 learners of English can potentially make more errors with passive constructions, favor active constructions over passive constructions, and even wrongly accept or use active constructions in the context where passives are necessary.

The underuse and overuse of passive constructions with two particular verb classes (i.e., psych verbs and unaccusative verbs) have already been observed in the studies conducted with Turkish learners of L2 English (i.e., Kurtoğlu, 2006; Montrual, 2001). What is deficient is a comparison between the acquisition of psych and unaccusative verbs from a processing point of view. As this view assumes that linguistic components necessitating less processing can be acquired earlier than those necessitating more processing, L2 learners of English can be expected to make more underpassivization errors with psych verbs than overpassivization errors with unaccusative verbs. Hence, the current research mainly intends to investigate Turkish EFL learners' acquisition of psych verbs and unaccusative verbs with a specific focus on underpassivization and overpassivization.

\section{Literature Review}

The literature suggests different hierarchies for thematic roles (e.g., Bresnan, 2001; Foley \& Van Valin, 1984; Givon, 1984; Jackendof, 1972) and grammatical functions (Keenan \& Comrie, 1977) as seen in (1) and (2) below.

(1) Thematic Hierarchy (Bresnan, 2001, p. 307)

Agent $>$ Beneficiary $>$ Experiencer/Goal $>$ Instrument $>$ Patient/Theme $>$ Locative

(2) Relational Hierarchy (Keenan \& Comrie, 1977)

( core ) ( non-core )

SUBJ $>$ OBJ $>$ OBJq $>$ OBJq $>$ COMPL $>$ ADJUNCT

Depending on the thematic and relational hierarchies, Pieneman et al. (2005) suggested the Lexical Mapping Hypothesis which has recently been resolved as follows: 
In second language acquisition learners will initially map the highest available role in the semantic hierarchy onto a minimally specified SUB/TOP. We call this: canonical mapping. Then they learn to map further arguments onto grammatical functions (GF) other than SUBJ or OBJ. Finally, they learn to attribute prominence to a particular thematic role lower in the semantic hierarchy by promoting it to SUBJ. At this stage they also learn to defocus the highest role by suppressing it or mapping it onto a GF other than SUBJ. We call these non-canonical mapping. (Kawaguchi, 2013, p. 93)

As detailed above, canonical mapping in English necessitates at least two arguments in its transitive actualization. Agent as the more prominent role is placed on Subject while Patient as the less prominent role is placed on Object position. There also exist some intransitive verbs (i.e., unergative verbs, e.g., cry) which shows a canonical mapping operation. The only argument of these verbs would be an Agent or Experiencer which is a high role in the thematic hierarchy and is mapped on Subject position.

(3) Canonical - transitive The dog ate the meat.

Agent Patient (thematic roles)

Subject Object (grammatical functions)

(4) Canonical - intransitive The child cried.

$\begin{array}{ll}\text { Agent } & \text { (thematic role) } \\ \text { Subject } & \text { (grammatical function) }\end{array}$

Apart from canonical mapping, two types of non-canonical mapping can be observed in English that are either structurally or lexically created. The noncanonical mapping created structurally "is usually called 'structural' because the alternative lexical entry creates a structural frame which is regular and predictable" (Kawaguchi, 2013, p. 96). This kind of non-canonical mapping can be exemplified with passive (e.g., active eat versus passive be eaten, (5)) and causative constructions (make X wash Y).

(5) Passive mapping

The meat was eaten by the dog.

$\begin{array}{ll}\text { Patient } & \text { Agent } \\ \text { Object } & \text { Subject }\end{array}$

The non-canonical mapping produced lexically, on the other hand, "are intrinsically required by the lexical verb" (Kawaguchi, 2013, p. 96), which makes them irregular and unpredictable as compared to the first one. So, the L2 learners need to discover and learn them as how the occasion requires. Two different verb classes which build non-canonical mappings in English and are within the scope of the current research are unaccusative verbs and psych verbs.

Unaccusative verbs are a sub-category of intransitive verbs which take Themes as their Subjects. This category of verbs includes verbs of occurrence (e.g., happen, occur), and dis/appearance (e.g., die, disappear; Levin, 1993, 
pp. 30, 258) which are defined as non-alternating unaccusatives since they do not have any transitive or passive alternatives (6).

(6) a. Unaccusative

b. Transitive

c. Passive
An accident happened.

\section{Theme}

*The woman happened an accident.

Subject

Theme

*The accident was happened.

\section{Theme}

The other verb type forming non-canonical mappings in English are psych verbs which are a subcategory of transitive verbs (e.g., frighten, surprise, disappoint; although intransitive use of them is possible for some verbs and forms, it is not a concern of the current paper), and they basically "describe the bringing about of a change in psychological or emotional state" (Levin, 1993, p. 189). In English, these verbs take at least two arguments in their transitive and passive use that are Theme and Experiencer. However, locating Experiencer in Subject position by using some psych verbs intransitively results in an ungrammatical use in English (see 7c).

(7) a. Transitive

b. Passive

c. Intransitive
The news surprised the people.

Theme Experiencer

The people were surprised at the news.

Experiencer Theme

The people were surprised when they heard the news.

Experiencer

*The people surprised when they heard the news. Experiencer

Hahn (2011) argues that if processability plays a role in the acquisition of English as an L2, passive constructions requiring more processing will be more difficult to acquire as compared to active constructions. Therefore, L2 learners of English can potentially make more errors with passive constructions, favor active constructions over passive constructions, and even wrongly accept or use active constructions in the context where passives are necessary. Since psych verbs map the Experiencer in the subject position (i.e., The people were surprised...), they can be regarded as a subcategory of passive constructions. This implies that the processing load of passivization is also valid for psych verb constructions, too. For this reason, L2 learners of English are supposed to deal with processing complexity of passivization in acquiring psych verb constructions.

The incorrect underuse of passives with psych verbs was documented in a study of Montrul (2001) conducted with Turkish learners of L2 English. Although intransitive psych verbs are accepted ungrammatical in English (i.e., *The hunter frightened), Turkish L2 learners were found to label this 
use of psych verbs as grammatical. Overpassivization can, on the other hand, be a probable area of errors for L2 learners of English. Turkish learners, for example, have been observed while overpassivizing in the contexts where they are supposed to prefer active construction with unaccusative verbs (Kurtoğlu, 2006). If Turkish learners are observed while making such an underpassivization error in (7c) more than the overpassivization error in (6c), the reason of learners' underpassivization in English psych verb constructions can stem from the processing complexity of passivization. This claim has also been supported by Kawaguchi (2013, p. 99) which indicated that "within lexically non-canonical mapping, ... unaccusatives are acquired before psych verbs." Therefore, the findings of the translation task conducted with Japanese L2 learners of English revealed the following acquisition order: canonical $>$ unaccusative verb $>$ psych verb.

The above few studies have indicated that Turkish learners of L2 English can underpassivize psych verbs and overpassivize unaccusative verbs. If processability account has a role in constraining L2 acquisition of English, linguistic dimensions necessitating less processing can be hypothesized to be acquired earlier than those necessitating more processing. Therefore, Turkish learners can commit more underpassivization errors with psych verbs as compared to overpassivization errors with unaccusative verbs. As no particular research has been conducted related to this issue with a specific reference to Turkish learners of L2 English, the current study has attempted to shed a humble light on it by investigating the acquisition of unaccusative and psych verbs simultaneously and comparatively. While quite a few studies (i.e., Kurtoğlu, 2006; Montrul, 2001) have investigated the nature of Turkish learners' acquisition of psych verbs and unaccusative verbs, no research have been conducted to examine these verbs together from a processing account of language acquisition and for a single set of subjects. The current study, therefore, aims to investigate Turkish L2 learners' acquisition of psych verbs and unaccusative verbs, and find out whether the development of these learners' interlanguage is constrained by the processability account of language acquisition or not. It also aims to investigate whether Turkish L2 learners' perceived word familiarity is related to their acquisition of psych verb and unaccusative verb constructions.

\section{Research Questions}

RQ1. Do ELT students perform more accurately on any verb type: psych verbs vs. unaccusative verbs?

RQ2. Do ELT students' performances on psych verbs and unaccusative verbs differ across their accuracy levels in GJT (i.e., low, medium, high)? 
RQ3. Do ELT students with low, medium and high accuracy of GJT perform better on any verb type: psych verbs vs. unaccusative verbs?

RQ4. Are ELT students more familiar with any verb type: psych verbs or unaccusative verbs?

RQ5. Is there any relationship between ELT students' degree of familiarity and level of accuracy with psych and unaccusative verbs?

RQ6. Do ELT students perform more accurately on any construction of psych and unaccusative verbs: passive vs. active constructions?

In parallel with these research questions, three main hypotheses developed by Hahn (2011) and reported below have been tested. Among them, RQ1 and RQ6 are relevant to Hypothesis 1, RQ2 and RQ3 are related to Hypothesis 2 while RQ4 and RQ5 are concerned with Hypothesis 3.

Hypothesis 1: Passives charge processing cost, and thus learners will make more errors due to underpassivization than overpassivization. As a result, psych verb constructions, which require passivization, will be more difficult to acquire than unaccusatives, which do not require it.

Hypothesis 2: Once learners reach a stage where passivization does not charge extra-cost, learners' underpassivization errors will reduce, and accordingly, their errors with psych verb constructions will decrease rapidly.

Hypothesis 3: Learners' difficulty with psych verb constructions and unaccusative constructions will not depend on their familiarity with individual verbs. (Hahn, 2011, p. 63)

\section{Method}

\section{Participants}

A total of 33 undergraduate-level university students enrolling in the program of English Language Teaching (ELT) at a state university of Turkey participated in the study. The participants consisted of first-year $(N=24$, $73 \%)$, second-year $(N=7,21 \%)$ and fourth-year $(N=2,6 \%)$ students. Of the 33 participants, 18 were females $(55 \%)$ and 15 were males (45\%). This group of students were chosen as the research sample because the current study was designed as a replication of the research conducted by Hahn (2011) whose participants were comprised of the university students studying English as their major and minor. The participants of the current study were members of the course called Critical Reading which is developed for the second half of first-year ELT program during the 2017-2018 academic year. The first-year 
program is also full of courses aiming to improve students' L2 (i.e., English) such as Contextual Grammar, Academic Reading, Written Communication, Listening Comprehension, Oral Communication Skills, and Academic Writing and Report Writing.

\section{Instruments}

Two different tasks developed by Hahn (2011) were applied in the current study: (1) Grammaticality Judgement Task (GJT) and (2) Word Familiarity Rating Task (WFRT). The first one, GJT, were a total of 38 items with 12 sentences for psych verbs, 12 sentences for unaccusative verbs, 12 sentences for distracters and two sentences for examples (see Appendix A). The GJT included six psych verbs (i.e., disappoint, embarrass, frighten, frustrate, shock, surprise) and six unaccusative verbs (i.e., arrive, die, disappear, fall, happen, occur) with which six pairs of grammatical and ungrammatical sentences were formed as exemplified in (8) and (9). It also includes 12 distracting sentences theorized to be problematic for L2 learners and serving the purpose of preventing the students from concentrating excessively on psych and unaccusative verb constructions. For more details related to task design process, you may take a look at the "Instrument and Procedure" section of Hahn (2011, pp. 63-66).

(8) Psych-verb constructions

Grammatical: The girl was disappointed when she found her grade. (Item 19)

Ungrammatical: The boy disappointed because he got a bad grade. (Item 31)

(9) Unaccusative-verb constructions

Grammatical: A letter from her mom arrived two days ago. (Item 34)

Ungrammatical: Your package was arrived a few hours ago. (Item 20)

The second task applied was the WFRT and it was a survey questioning familiarity with a total of 12 psych and unaccusative verbs (see Appendix B). In this task, the participants were supposed to indicate their degrees of familiarity with individual psych and unaccusative verbs on a 4-point Likert scale ranging from " 1 = very unfamiliar" to " 4 = very familiar."

\section{Data Collection and Analysis}

The data were collected in the second semester of 2017-2018 academic year at a Turkish state university in Turkey. The participants were from the two sections of Critical Reading class and the study was conducted during class time. The two tasks were implemented at the same time with GJT being the 
first and WFRT being the second one asked to be filled out. Different from the previous study (Hahn, 2011), an untimed application of the GTJ was preferred because of practical reasons, and additionally, participants were requested not to turn back and revise their responses for the task. "Volunteer participation" was an adopted criterion during the data collection process therefore only the students having this volunteerism performed the two target tasks by signing the certificate of consent (see Appendix A).

As for data analysis, firstly, the individual performances of the participants were calculated. In GJT, each accurate response corresponded to " 1 " point while each inaccurate response corresponded to " 0. " The sum of the points participants collected from GJT was equivalent to their accuracy scores. In addition to the total score of GJT, the scores for psych verb and unaccusative verb constructions as well as distracters were also calculated. As for WFRT, degree of familiarity with psych and unaccusative verbs were determined according to the values chosen by the participants on the 4-point Likert scale. Therefore, the familiarity degree of each participant for individual and two groups of verbs ranged across 1, 2, 3, and 4. Based on these scores, descriptive statistics were tabulated and a set of nonparametric tests were conducted with the aim of answering research questions.

In order to answer RQ1 (i.e., Do ELT students perform more accurately on psych verbs or unaccusative verbs?), a Wilcoxon Signed-Ranks Test was conducted to compare the participants' performances on psych and unaccusative verbs. To investigate (RQ2) whether ELT students' performances on psych verbs and unaccusative verbs differ across their accuracy levels in GJT (i.e., low, medium, high), two different Kruskal-Wallis Tests were conducted, which was followed by a sets of Mann-Whitney U tests as follow-ups. For RQ3 (i.e., Do ELT students with low, medium and high accuracy of GJT perform better on any verb type including psych verbs and unaccusative verbs?), three different Wilcoxon Signed-Ranks Tests were performed to compare the performances of low, moderate and high accurate participants on psych and unaccusative verbs. In order to find out whether ELT students are more familiar with psych verbs or unaccusative verbs (RQ4), a Wilcoxon Signed-Ranks Test was conducted to compare the participants' degree of familiarity with psych and unaccusative verbs. The Pearson correlation coefficient was used to investigate the possible relationship between degree of familiarity and level of accuracy with psych and unaccusative verbs (RQ5). Lastly, so as to investigate whether ELT students perform more accurately on any of the two constructions of psych and unaccusative verbs (i.e., passive vs. active constructions), two sets of Wilcoxon Signed-Ranks Tests were conducted (RQ6). In addition to these nonparametric tests, descriptive statistics of the related variables were also reported in the Results section in a detailed manner. 


\section{Results}

As a first step to data analysis, the normality of the data has been tested. A Shapiro-Wilk's Test $(p=.031)$ and the visuals of histograms, normal Q-Q plots and box plots showed that the data from GJT were not normally distributed, with a skewness of $-0.539(S E=0.409)$ and a kurtosis of $-0.769(S E=$ 0.798). Also, the data from WFRT were found not to be normally distributed with a skewness of $-1.572(S E=0.409)$ and a kurtosis of $2.786(S E=0.798)$. As the assumption of normality has not been met for this sample, the researchers used nonparametric tests for the analyses.

Table 1.

Descriptive statistics: Psych-v, unaccusative-v, other structures and GJT

\begin{tabular}{lcccccc}
\hline & $N$ & Min. & Max. & Mean & Std. Deviation & Std. Error Mean \\
\hline GJT_Psych-V & 33 & 1 & 12 & 9.424 & 2.598 & 0.452 \\
GJT_Unaccusative-V & 33 & 3 & 12 & 9.787 & 1.916 & 0.333 \\
GJT_Other Structures & 33 & 5 & 11 & 8.545 & 1.715 & 0.298 \\
GJT (Total) & 33 & 18 & 35 & 27.757 & 4.416 & 0.768 \\
\hline
\end{tabular}

As indicated in the Table 1, the participants of the current study performed more accurately on unaccusative verbs $(M=9.787, S D=1.916)$ than on psych verbs $(M=9.424, S D=2.598)$.

Table 2.

Wilcoxon Signed-Rank Test: Psych-v vs. unaccusative-v in GJT

\begin{tabular}{lrcccc}
\hline $\begin{array}{l}\text { GJT_Unaccusative-V } \\
\text { GJT_Psych-V }\end{array}$ & $N$ & Mean Rank & Sum of Ranks & $Z$ & $p$ \\
\hline Negative Ranks & 12 & 13.75 & 165 & $-.583^{*}$ & .560 \\
Positive Ranks & 15 & 14.20 & 213 & & \\
Equal & 6 & & & & \\
TOTAL & 33 & & & & \\
\hline
\end{tabular}

*Based on negative ranks.

To answer RQ1 (i.e., Do first-year ELT students perform more accurately on any verb type: psych verbs vs. unaccusative verbs?) the following step was to conduct a Wilcoxon Signed-Ranks Test in order to compare the performances of the participants for two types of constructions: psych verbs $(M d n=10)$ and unaccusative verbs $(M d n=10)$. The results (see Table 2) indicated that despite the values found by the descriptive statistics (Table 2), 
unaccusative verb ranks were not statistically significantly higher than psych verb ranks $(Z=-0.583, p>.05)$.

Table 3.

The formula applied to calculate three accuracy levels in GJT

\begin{tabular}{ll}
\hline Low & $M-S D=Y(Y$ and above scores $)$ \\
\hline Medium & $M+S D=X$ and $M-S D=Y($ The scores between $X$ and $Y)$ \\
$Y$ High & $M+S D=X(X$ and above scores $)$ \\
\hline
\end{tabular}

To answer RQ2 (i.e., Do first-year ELT students' performances on psych verbs and unaccusative verbs differ across their accuracy levels in GJT (i.e., low, medium, high)?), firstly, the accuracy profile of the participants for GJT have been decided. For this purpose, the accuracy score of each participant for GJT has been calculated. While scoring the participants' responses for the task, each accurate response corresponded to "1" point. Each inaccurate response, on the other hand, corresponded to " 0 " point. Therefore, the sum of the points participants collected for 36 items composed the accuracy score for GJT. As stated in Table 3, the mean value and the standard deviation of the mean for GJT were found as follows: $M=27.757, S D=4.416$. Based on these values, the obtained accuracy scores in GJT were divided into three levels as Low-Accurate, Medium-Accurate and High-Accurate using the formula detailed in Table 3.

Table 4.

The accuracy profiles of the participants for GJT

\begin{tabular}{llcccc}
\hline Level & Accuracy in GJT & Min. & Max. & $N$ & [\%] \\
\hline Low-accurate & 23 and below & 18 & 23 & 7 & 21 \\
Medium-accurate & between 23 and 32 & 24 & 31 & 20 & 61 \\
High-accurate & 32 and above & 32 & 35 & 6 & 18 \\
\hline TOTAL & & & & 33 & 100 \\
\hline
\end{tabular}

As a result, the participants with the accuracy scores of " 23 " and below were determined as low-accurate $(N=7,21 \%)$ while the ones with the accuracy scores of "32" and above were decided as high-accurate $(N=20,61 \%)$. The rest of the participants having the accuracy scores between " 23 " and " 32 " were, on the other hand, defined as medium-accurate $(N=6,18 \%)$ as depicted in Table 4. 
Table 5 .

Descriptive statistics: Accuracy for psych-v and unaccusative-v across 3-levels in GJT

\begin{tabular}{lcccccc}
\hline & \multicolumn{3}{c}{ GJT_Psych-V } & \multicolumn{3}{c}{ GJT_Unaccusative-V } \\
\cline { 2 - 7 } Accuracy Level GJT & Mean & $\begin{array}{c}\text { Std. } \\
\text { Deviation }\end{array}$ & $\begin{array}{c}\text { Std. Error } \\
\text { Mean }\end{array}$ & Mean & $\begin{array}{c}\text { Std. } \\
\text { Deviation }\end{array}$ & $\begin{array}{c}\text { Std. Error } \\
\text { Mean }\end{array}$ \\
\hline Low $(N=7)$ & 6.571 & 2.820 & 1.065 & 8.142 & 2.609 & 0.986 \\
Medium $(N=20)$ & 9.850 & 1.926 & 0.430 & 9.900 & 1.447 & 0.323 \\
High $(N=6)$ & 11.833 & 0.408 & 0.166 & 11.333 & 0.816 & 0.333 \\
\hline
\end{tabular}

In Table 5, the related values of low-accurate, medium-accurate and highaccurate participants for psych verbs and unaccusative verbs have been tabulated. As seen in the table, the mean scores of low and medium accurate participants for unaccusative verbs $(M=8.14, S D=2.60$ and $M=9.90, S D=1.44$ respectively) are higher than their mean scores for psychverbs $(M=6.57$, $S D=2.82$ and $M=9.85, S D=1.92)$. But, the situation is totally opposite for the high-accurate participants. Their scores for psych-verbs $(M=11.83, S D=0.40)$ are higher than their scores for unaccusitive-verbs $(M=11.33, S D=0.81)$. In addition to the descriptive statistics, a set of non-parametric tests (i.e., KruskalWallis Test) have also been conducted in order to discover the performances on psych verbs and unaccusative verbs across three GJT accuracy levels.

Table 6.

Kruskal-Wallis Test: Psych-v and unaccusative-v across 3 accuracy levels of GJT

\begin{tabular}{|c|c|c|c|c|c|c|}
\hline Accuracy Score & Groups & $N$ & Mean Rank & Chi-square & $d f$ & $p$ \\
\hline \multirow[t]{4}{*}{ GJT_Psych-V } & Low & 7 & 6.21 & \multirow{4}{*}{15.733} & \multirow{4}{*}{2} & \multirow{4}{*}{0.000} \\
\hline & Intermediate & 20 & 17.78 & & & \\
\hline & High & 6 & \multirow[t]{2}{*}{27.00} & & & \\
\hline & TOTAL & 33 & & & & \\
\hline \multirow[t]{4}{*}{ GJT_Unaccusative-V } & Low & 7 & 9.64 & \multirow{4}{*}{10.071} & \multirow{4}{*}{2} & \multirow{4}{*}{0.007} \\
\hline & Intermediate & 20 & 16.78 & & & \\
\hline & High & 6 & 26.33 & & & \\
\hline & TOTAL & 33 & & & & \\
\hline
\end{tabular}

The results of the Kruskal-Wallis Test (see Table 6) indicated that there is a statistically significant difference among three group of learners' performances on psych verb constructions $(H(2)=15.733, p<.001)$, with a mean rank of 6.21 for the low-accurate students, 17.78 for the medium-accurate students and 27 for the high-accurate students. The same statistically significant difference 
also exists among learners' performances on unaccusative-verb constructions $(H(2)=10.071, \mathrm{p}<.001)$, with a mean rank of 9.64 for the low-accurate students, 16.78 for the medium-accurate students and 26.33 for the high-accurate students. These findings show us that as the total level of accuracy in GJT increases, the level of accuracy with psych verbs and unaccusative verbs increase individually, too.

A series of Mann-Whitney U Tests were conducted as follow-ups in order to detect the significant differences in verb accuracy occurring across three different general accuracy levels (i.e., low, intermediate, and high). The results indicated significant differences between the unaccusative verb scores of low $(M d n=9)$ and high $(M d n=11.5)$ accurate $(U=2.5, p=.007)$, and medium $(M d n=10)$ and high $(M d n=11.5)$ accurate participants $(U=22.5, p=.019)$ while the difference is not significant between the scores of low $(M d n=9)$ and medium $(M d n=10)$ accurate participants $(U=37, p=.062)$. They also revealed significant differences between the psych verb scores of low $(M d n=$ $7)$ and medium $(M d n=10)$ accurate $(U=19, p=.004)$, low $(M d n=7)$ and high $(M d n=12)$ accurate $(U=0, p=.002)$, and medium $(M d n=10)$ and high $(M d n=12)$ accurate participants $(U=16.5, p=.006)$.

Table 7.

Wilcoxon Signed-Rank Test: Psych-v vs. unaccusative-v with low-accuracy in GJT

\begin{tabular}{lccccc}
\hline $\begin{array}{l}\text { GJT_Unaccusative-V_Low } \\
\text { GJT_Psych V_Low }\end{array}$ & $N$ & Mean Rank & Sum of Ranks & $Z$ & $p$ \\
\hline Negative Ranks & 2 & 3.25 & 6.50 & $-0.841^{*}$ & .400 \\
Positive Ranks & 4 & 3.63 & 14.50 & & \\
Equal & 1 & & & & \\
TOTAL & 7 & & & & \\
\hline
\end{tabular}

* Based on negative ranks.

As indicated in the Table 5, the low-accurate participants performed more accurately on unaccusative verbs $(M=8.142, S D=2.609)$ than on psych verbs $(M=6.571, S D=2.820)$. In order to answer RQ3 (i.e., Do first-year ELT students with low, medium and high accuracy of GJT perform better on any verb type including psych verbs and unaccusative verbs?), the following step was to conduct a set of Wilcoxon Signed-Ranks Test in order to compare the performances of the low-accurate participants for two types of constructions: psych verbs $(M d n=7)$ and unaccusative verbs $(M d n=8)$. The results (see Table 7) indicated that unaccusative verb ranks were not statistically significantly higher than psych verb ranks $(Z=-0.841, p>.05)$. 
Table 8.

Wilcoxon Signed-Rank Test: Psych-v vs. unaccusative-v with medium-accuracy in $G J T$

\begin{tabular}{lrcccc}
\hline $\begin{array}{l}\text { GJT_Unaccusative-V_Medium } \\
\text { GJT_Psych-V_Medium }\end{array}$ & $N$ & Mean Rank & Sum of Ranks & $Z$ & $p$ \\
\hline Negative Ranks & 9 & 10 & 90 & $-0.204^{*}$ & .839 \\
Positive Ranks & 10 & 10 & 00 & & \\
Equal & 1 & & & & \\
TOTAL & 20 & & & & \\
\hline
\end{tabular}

* Based on negative ranks.

The same result is also valid for the medium-accurate and high-accurate participants. The medium-accurate participants performed slightly more accurately on unaccusative verbs $(M=9.90, S D=1.447)$ than on psych verbs $(M=9.85, S D=1.926)$. In order to compare the performances of the medium-accurate participants for psych verb $(M d n=10)$ and unaccusative verb $(M d n=10)$ constructions, the following step was to conduct a Wilcoxon Signed-Ranks Test. The results (Table 8 ) indicated that unaccusative verb ranks were not statistically significantly higher than psych verb ranks $(Z=-0.203$, $p>.05)$.

Table 9 .

Wilcoxon Signed-Rank Test: Psych-v vs. unaccusative-v with high-accuracy in GJT

\begin{tabular}{lccccc}
\hline $\begin{array}{l}\text { GJT_Unaccusative-V_High } \\
\text { GJT_Psych-V_High }\end{array}$ & $N$ & Mean Rank & Sum of Ranks & $Z$ & $p$ \\
\hline Negative Ranks & 2 & 1.50 & 3.00 & $-1.342^{*}$ & .180 \\
Positive Ranks & 0 & .00 & .00 & & \\
Equal & 4 & & & & \\
TOTAL & 6 & & & & \\
\hline
\end{tabular}

*Based on positive ranks.

The high-accurate participants, on the other hand, performed slightly more accurately on psych verbs $(M=11.833 ; S D=0.408)$ than on unaccusative verbs $(M=11.333 ; S D=0.816)$. In order to answer $\mathbf{R Q 3}$, one more Wilcoxon Signed-Ranks Test was conducted in order to compare the performances of the high-accurate participants for psych verb $(M d n=12)$ and unaccusative verb $(M d n=11.5)$ constructions. The results (Table 9) indicated that psych verb ranks were not statistically significantly higher than unaccusative-verb ranks $(Z=-1.342, p>.05)$. 
Table 10.

Descriptive statistics: Psych-v and unaccusative-v in WFRT

\begin{tabular}{lcccccc}
\hline & $N$ & Min. & Max. & Mean & Std. Deviation & Std. Error Mean \\
\hline WFRT_Psych-V & 33 & 1 & 4 & 3.300 & 0.825 & 0.143 \\
WFRT_Unaccusative-V & 33 & 1 & 4 & 3.442 & 0.718 & 0.125 \\
\hline
\end{tabular}

The values in descriptive statistics (Table 10) indicate that the ELT students are more familiar with unaccusative verbs $(M=3.442, S D=0.718)$ than psych verbs $(M=3.300, S D=0.825)$. In addition to descriptive statistics, a nonparametric test (i.e., a Wilcoxon Signed-Ranks Test) was also conducted in order to answer RQ4 (i.e., Are first-year ELT students more familiar with any verb type including psych verbs or unaccusative verbs?). The aim was to compare the participants' degree of familiarity with psych verbs $(M d n=3.666)$ and unaccusative verbs $(M d n=3.666)$.

Table 11.

Wilcoxon Signed-Rank Test: Familiarity with psych-v vs. unaccusative-v

\begin{tabular}{lrcccc}
\hline $\begin{array}{l}\text { WFRT_Unaccusative-V } \\
\text { WFRT_Psych-V }\end{array}$ & N & Mean Rank & Sum of Ranks & Z & p \\
\hline Negative Ranks & 7 & 12 & 84 & $-1.650^{*}$ & .099 \\
Positive Ranks & 16 & 12 & 192 & & \\
Equal & 10 & & & & \\
TOTAL & 33 & & & & \\
\hline
\end{tabular}

* Based on negative ranks.

The results (Table 11) indicated that unaccusative verb ranks were not statistically significantly higher than psych verb ranks $(Z=-1.650$, $p=.099)$. Although a slight difference is observed between familiarity means of two types of verbs (Table 10), this difference is not at any significant level. Meanwhile, Table 12 below also indicates that the familiarity ranks of two types of verbs (i.e., psych (six verbs) and unaccusative (six verbs)) do not also match up with the accuracy ranks of the same verbs in GJT, which has been detailed below. 
Table 12.

Familiarity (WFRT) and accuracy (GJT) ranks \& means of psych-v and unaccusative-v

\begin{tabular}{lcccc}
\hline Verb & Familiarity Rank & Mean_WFRT & Accuracy Rank & Mean_GJT \\
\hline Happen_Unaccusative-V & 1 & 3.67 & 2 & 1.787 \\
Surprise_Psych-V & 2 & 3.59 & 9 & 1.484 \\
Shock_Psych-V & 3 & 3.55 & 3 & 1.727 \\
Die_Unaccusative-V & 4 & 3.52 & 1 & 1.818 \\
Disappoint_Psych-V & 4 & 3.52 & 11 & 1.393 \\
Fall_Unaccusative-V & 5 & 3.48 & 5 & 1.666 \\
Disappear_Unaccusative-V & 6 & 3.42 & 7 & 1.575 \\
Arrive_Unaccusative-V & 7 & 3.38 & 10 & 1.424 \\
Embarrass_Psych-V & 8 & 3.19 & 4 & 1.697 \\
Occur_Unaccusative-V & 9 & 3.18 & 8 & 1.515 \\
Frighten_Psych-V & 10 & 3.12 & 6 & 1.606 \\
Frustrate_Psych-V & 11 & 2.91 & 8 & 1.697 \\
\hline
\end{tabular}

In Table 12, the familiarity and accuracy ranks/means for individual psych and unaccusative verbs have been reported. The familiarity ranks of the verbs have been tabulated in a descending order, which means that the participants are found to be most familiar with happen and least familiar with frustrate. However, the verb that the participants performed on most accurately is die, while disappoint is observed to be the most challenging one. All in all, the values in Table 13 indicate very little correspondence between the familiarity and accuracy ranks/means of the verbs.

The answer to the RQ5 (i.e., Is there any relationship between first-year ELT students' degree of familiarity and level of accuracy with psych and unaccusative verbs?) also supports the finding above (Table 13) because the participants' degree of familiarity with and accuracy level for psych verbs $(r=.174 ; p=.203>.05)$ do not correlate with each other at any significant level. The same result is also valid for unaccusative verbs since the participants' degree of familiarity with and accuracy level for unaccusative verbs $(r=-.257$, $p=.262>.05)$ do not also correlate with each other at any significant level. So much so that, unaccusative verbs show a negative correlation between its degree of familiarity and accuracy level.

In addition to grouping the two verb categories, degree of familiarity and accuracy level of each verb was compared individually too. The results indicated no significant relationship between familiarity degrees and accuracy levels of six different psych verbs (disappoint $(r=-.271, p=.127)$; embarrass $(r=.096$, $p=.596)$; frighten $(r=.325, p=.065)$; frustrate $(r=.272, p=.126)$; shock 
$(r=.120, p=.508)$, surprise $(r=.068, p=.705))$. The same result was also observed for six different unaccusative verbs (arrive $(r=-.028, p=.877)$; die $(r=-.247, p=.166)$; disappear $(r=-.212, p=.236)$; fall $(r=.085, p=.636)$; happen $(r=.181, p=.313)$; occur $(r=-.111, p=.538)$.

Table 13.

Accuracy for psych-v constructions: Number \& rate of the participants

\begin{tabular}{|c|c|c|c|c|c|}
\hline & & & Items & $N(33)$ & [\%] \\
\hline Item 8 & (G) & $\mathrm{P}$ & $\begin{array}{l}\text { The little girl was frightened, so she called the } \\
\text { police. }\end{array}$ & 31 & 93.9 \\
\hline Item 13 & (G) & $\mathrm{P}$ & $\begin{array}{l}\text { He was embarrassed because he could not } \\
\text { speak English. }\end{array}$ & 30 & 90.9 \\
\hline Item 35 & (G) & $\mathrm{P}$ & Everyone was shocked to hear the news. & 30 & 90.9 \\
\hline Item 23 & (G) & $\mathrm{P}$ & $\begin{array}{l}\text { The people were frustrated because they lost all } \\
\text { the money. }\end{array}$ & 28 & 84.8 \\
\hline Item 16 & (UNG) & $A$ & All the people shocked to hear the news. & 27 & 81.8 \\
\hline Item 21 & (G) & $\mathrm{P}$ & The hikers were surprised to see a big bear. & 27 & 81.8 \\
\hline Item 26 & (UNG) & A & $\begin{array}{l}\text { The teacher embarrassed because she made } \\
\text { a mistake. }\end{array}$ & 26 & 78.8 \\
\hline Item 19 & (G) & $\mathrm{P}$ & $\begin{array}{l}\text { The girl was disappointed when she found her } \\
\text { grade. }\end{array}$ & 23 & 69.7 \\
\hline Item 31 & (UNG) & A & $\begin{array}{l}\text { The boy disappointed because he got a bad } \\
\text { grade. }\end{array}$ & 23 & 69.7 \\
\hline Item 3 & (UNG) & $A$ & The woman surprised to hear the loud noise. & 22 & 66.7 \\
\hline Item 29 & (UNG) & A & The cat frightened when it saw a big dog. & 22 & 66.7 \\
\hline Item 11 & (UNG) & $A$ & $\begin{array}{l}\text { The woman frustrated because she could not find } \\
\text { help. }\end{array}$ & 22 & 66.7 \\
\hline
\end{tabular}

$\mathrm{G}=$ Grammatical, $\mathrm{UNG}=$ Ungrammatical, $\mathrm{P}=$ Passive, $\mathrm{A}=$ Active

Table 13 shows the number and rate of participants accurately responding to the twelve items of psych verb constructions in GJT. As the symbols $N$ and [\%] indicate, the number and rates of participants making accurate judgements for the listed items are higher for the passive construction of psych verbs than active construction of it. The first four lines followed by the sixth and eighth lines of the table include passive constructions with higher number and rates of participants responding accurately to the related items. This finding has also been verified by the nonparametric test results reported below. 
Table 14.

Wilcoxon Signed-Rank Test: Active vs. passive constructions of psych-v

\begin{tabular}{lccccc}
\hline $\begin{array}{l}\text { GJT_Psych-V_Active } \\
\text { GJT_Psych-V_Passive }\end{array}$ & $N$ & Mean Rank & Sum of Ranks & $Z$ & $p$ \\
\hline Negative Ranks & 15 & 13.6 & 204 & $-2.582^{*}$ & .010 \\
Positive Ranks & 7 & 7 & 49 & & \\
Equal & 11 & & & & \\
TOTAL & 33 & & & & \\
\hline
\end{tabular}

* Based on positive ranks.

In order to answer RQ6 (i.e., Do first-year ELT students perform more accurately on any construction of psych and unaccusative verbs (i.e., passive vs. active constructions)?), a Wilcoxon Signed-Ranks Test was conducted in order to compare the participants' degree of accuracy for the two types of psych verb constructions: passive $(M=5.121 ; S D=1.192 ; M d n=5)$ and active $(M=$ 4.303; $S D=1.811 ; M d n=5$ ). The results (Table 14) indicated that psych verb passive construction ranks were statistically significantly higher than psych verb active construction ranks $(Z=-2.582, p \leq .01)$.

Table 15.

Accuracy for unaccusative-v constructions: Number \& rate of the participants

\begin{tabular}{lcclcc}
\hline & & Items & N (33) & {$[\%]$} \\
\hline Item 30 & $(\mathrm{G})$ & A & $\begin{array}{l}\text { Their parents died of cancer when they were } \\
\text { young. }\end{array}$ & 32 & 97 \\
Item 25 & $(\mathrm{G})$ & A & A terrible accident happened last night. & 31 & 93.9 \\
Item 18 & $(\mathrm{UNG})$ & P & Several storms were occurred in Seattle last year. & 30 & 90.9 \\
Item 7 & $(\mathrm{G})$ & A & The boy fell into the swimming pool. & 28 & 84.8 \\
Item 9 & $(\mathrm{UNG})$ & P & Her mother was died of cancer 5 years ago. & 28 & 84.8 \\
Item 37 & $(\mathrm{UNG})$ & P & So many things were happened to her last week. & 28 & 84.8 \\
Item 27 & $(\mathrm{UNG})$ & P & The girl was disappeared into the forest. & 27 & 81.8 \\
Item 33 & $(\mathrm{UNG})$ & P & The cup was fallen from the table. & 27 & 81.8 \\
Item 20 & $(\mathrm{UNG})$ & P & Your package was arrived a few hours ago. & 26 & 78.8 \\
Item 15 & $(\mathrm{G})$ & A & The thief disappeared into the dark. & 25 & 75.8 \\
Item 34 & $(\mathrm{G})$ & A & A letter from her mom arrived two days ago. & 21 & 63.6 \\
Item 4 & $(\mathrm{G})$ & A & Several fires occurred in Seoul last year. & 20 & 60.6 \\
\hline
\end{tabular}

$\mathrm{G}=$ Grammatical, $\mathrm{UNG}=$ Ungrammatical, $\mathrm{P}=$ Passive, $\mathrm{A}=$ Active

Table 15 shows the number and rate of participants accurately responded to the twelve items of unaccusative verb constructions in GJT. As the symbol $N$ and $[\%]$ indicate, the number and rate of participants making accurate judge- 
ments for the listed items do not show a certain accumulation neither for passive construction nor for active construction of unaccusative verbs. The first two lines followed by the fourth of the table include active constructions while the third and the following five lines include passive constructions. This discrete distribution has also been verified by the nonparametric test results reported below.

Table 16.

Wilcoxon Signed-Rank Test: Active vs. passive constructions of unaccusative-v

\begin{tabular}{lrcccc}
\hline $\begin{array}{l}\text { GJT_Unaccusative-V_Active } \\
\text { GJT_Unaccusative-V_Passive }\end{array}$ & $N$ & Mean Rank & Sum of Ranks & $Z$ & $p$ \\
\hline Negative Ranks & 14 & 10.21 & 143 & $-1.481^{*}$ & .139 \\
Positive Ranks & 6 & 11.17 & 67 & & \\
Equal & 13 & & & & \\
TOTAL & 33 & & & & \\
\hline
\end{tabular}

* Based on positive ranks.

For RQ6, one more Wilcoxon Signed-Ranks Test was also conducted in order to compare the participants' level of accuracy for the two types of unaccusative verb constructions: passive $(M=5.030 ; S D=1.237 ; M d n=5)$ and active $(M=4.757 ; S D=0.969 ; M d n=5)$. The results (Table 16) indicated that unaccusative verb passive construction ranks were not statistically significantly higher than unaccusative verb active construction ranks $(Z=-1.481, p=.139)$.

Table 17.

Wilcoxon Signed-Rank Test: unaccusative-v passive constructions vs. psych-v active constructions

\begin{tabular}{lccccc}
\hline $\begin{array}{l}\text { GJT_Unaccusative-V_Passive } \\
\text { GJT_Psych-V_Active }\end{array}$ & $N$ & Mean Rank & Sum of Ranks & $Z$ & $p$ \\
\hline Negative Ranks & 8 & 9.75 & 78 & $-1.844^{*}$ & .065 \\
Positive Ranks & 15 & 13.20 & 198 & & \\
Equal & 10 & & & & \\
TOTAL & 33 & & & & \\
\hline
\end{tabular}

For RQ6, one more Wilcoxon Signed-Ranks Test was also conducted in order to compare the participants' level of accuracy for the passive constructions of unaccusative-verb $(M=5.030 ; S D=1.237 ; M d n=5)$ and active constructions of psych verbs $(M=4.303 ; S D=1.811 ; M d n=5)$. The results (Table 17) indicated that unaccusative verb passive construction ranks were not statistically significantly higher than psych verb active construction ranks $(Z=-1.844, p=.065)$. 
Table 18.

Wilcoxon Signed-Rank Test: unaccusative-v active constructions vs. psych-v passive constructions

\begin{tabular}{lrcccc}
\hline $\begin{array}{l}\text { GJT_Unaccusative-V_Active } \\
\text { GJT_Psych-V_Passive }\end{array}$ & $N$ & Mean Rank & Sum of Ranks & $Z$ & $p$ \\
\hline Negative Ranks & 15 & 11.77 & 176 & $-1.677^{*}$ & .094 \\
Positive Ranks & 7 & 10.93 & 76.5 & & \\
Equal & 11 & & & & \\
TOTAL & 33 & & & & \\
\hline
\end{tabular}

* Based on positive ranks.

For RQ6, the last Wilcoxon Signed-Ranks Test was conducted in order to compare the participants' level of accuracy for the active constructions of unaccusative verb $(M=5.121 ; S D=1.192 ; M d n=5)$ and passive constructions of psych verbs $(M=4.757 ; S D=0.969 ; M d n=5)$. The results (Table 18) indicated that unaccusative verb active construction ranks were not statistically significantly higher than psych verb passive construction ranks $(Z=-1.677$, $p=.094)$.

\section{Discussion}

Hypothesis 1 claimed that it would be difficult to acquire psych verb constructions than unaccusative verb constructions since passives charge processing cost. For this reason, the participants had been hypothesized to be making more underpassivization errors than overpassivization errors. The above results confirmed the first hypothesis of the study to some extent. The descriptive statistics indicated that the participants performed more accurately on unaccusative verbs than on psych verbs; however, this accuracy difference was not statistically significant (RQ1). Therefore, there is still a possibility of this result to emerge by chance. Also, the result related to the participants' accuracy on active and passive constructions of psych verbs indicated that psych verb passive construction ranks were statistically significantly higher than psych verb active construction ranks. This result shows us that the participants did more underpassivization errors by accepting the ungrammatical active constructions of psych verbs (e.g., The cat frightened when it saw a big dog) as correct and by performing more accurately on passive constructions of psych verbs. (e.g., The little girl was frightened, so she called the police). In contrast, the difference between participants' accuracy levels for passive (e.g., The girl was dis- 
appeared into the forest) and active (e.g., The thief disappeared into the dark) unaccusative verb constructions were not statistically significant.

The above analyses also demonstrated that the performances on psych verbs and unaccusative verbs go parallel with their general accuracy levels in GJT. Once the participants' accuracy levels in GJT increased, their underpassivization errors, in other words, their errors with psych verb constructions decreased synchronously. The same result is valid for unaccusative verb constructions with an exception that is the low and medium level participants' performances are close to each other for this verb class. This exception can suggest that unaccusative verbs are acquired at the later levels of proficiency because low and moderate-level student performances do not differentiate from each other.

When the performances of low, medium and high-level participants on psych verbs and unaccusative verbs were compared, it was found that the low, medium and high-level participants did not perform differently on psych and unaccusative verbs. In other words, the low-levels performed less accurately both on psych and unaccusative verbs while the high-levels performed more accurately on both verb types. This suggests that the difficulty level of psych and unaccusative verb constructions do not vary for the same level of learners. Therefore, once learners reach a stage, both underpassivization and overpassivization errors reduced, the gap in the performances between psych and unaccusative constructions did not enlarge and none of them got any advantage over the other. Therefore, the Hypothesis 2 was not confirmed by the current results.

As for the Hypothesis 3, it is not possible to regard degree of familiarity as a source of accuracy for psych and unaccusative verbs. The results firstly indicated that the participants' degree of familiarity with two verb types did not vary from each other. Moreover, their degree of familiarity with and accuracy level for unaccusative and psych verbs do not correlate with each other at any significant level. Even, these two variables demonstrated a reverse relationship for some unaccusative (i.e., arrive, die, disappear, occur) and psych (i.e., disappoint) verbs. Therefore, it can be concluded that the participants' performance on psych and unaccusative verbs in the GJT was not influenced by their perceived degree of familiarity with these verb types, which confirms the third hypothesis of the study.

The performance difference raised between active (ungrammatical) and passive (grammatical) constructions of psych verbs implies that the participants do not have as much difficulty in approving the grammatical (passive) constructions as they do in rejecting the ungrammatical (Active) constructions. They were, instead, inclined to regard active constructions (e.g., The cat frightened when it saw a big dog) as correct. As the participants' accuracy for psych verbs do not correlate significantly with their familiarity, and as their performance on active and passive constructions of psych verbs differentiate at a significant level, the participants' responses to two different constructions 
rather than individual verbs can be interpreted as their actual performances. As seen in Table 13, except "disappoint" (since the number/ratio of participants responding accurately for two constructions were equal for "disappoint"), all the passive constructions of five psych verbs were outperformed in contrast with their active constructions.

As for unaccusative verbs, the participants' level of accuracy for passive and active constructions were not statistically significantly different from each other. Instead, it is possible to observe some differences in verb level. For instance, while the grammatical constructions (i.e., active) of the verbs die, fall, and happen are accepted more accurately than their ungrammatical constructions (i.e., passive), it is totally opposite for the other three verbs (i.e., arrive, disappear, occur). For these verbs, it was more difficult for the participants to approve grammatical items than rejecting ungrammatical ones. Therefore, it is possible to state that the participants' performances vary across different verbs. One possible explanation for this variety can be the different levels of exposure to these verbs throughout their language acquisition process.

The potential support for this rationale can come from the lists of word frequencies in English. While die, fall, and happen, for example, are among the frequent words according to the two common wordlists (i.e., New General Service List (NGSL) and BNC/COCA Headword List), the other three verbs, arrive, disappear and occur, are in higher rankings of these lists (see Table 19). Also, English Vocabulary Profile (EVP) reports that die, fall, and happen are used by $\mathrm{L} 2$ English learners at the levels of A1, A2, and A2 respectively while arrive, disappear and occur are found to be used by the learners at A2, B1, and B2 levels. Table 19.

Accuracy (GJT), familiarity (WFRT) and frequency (NGSL, BNC/COCA Headword List, EVP) ranks of psych-v and unaccusative-v

\begin{tabular}{lccccc}
\hline Verb & $\begin{array}{c}\text { Accuracy } \\
\text { Rank }\end{array}$ & $\begin{array}{c}\text { Familiarity } \\
\text { Rank }\end{array}$ & NGSL & $\begin{array}{c}\text { BNC/COCA } \\
\text { Headword List }\end{array}$ & EVP \\
\hline Die_Unaccusative-V & 1 & 4 & 493 & 1st 1000 & A1 \\
\hline Happen_Unaccusative-V & 2 & 1 & 245 & 1st 1000 & A2 \\
\hline Shock_Psych-V & 3 & 3 & 4118 & 2nd 1000 & B2 \\
\hline Embarrass_Psych-V & 4 & 8 & 2576 & 2nd 1000 & C2 \\
\hline Fall_Unaccusative-V & 5 & 5 & 353 & 1st 1000 & A2 \\
\hline Frighten_Psych-V & 6 & 10 & 2249 & 1st 1000 & B2 \\
\hline Disappear_Unaccusative-V & 7 & 6 & 1762 & 2nd 1000 & B1 \\
\hline Frustrate_Psych-V & 8 & 11 & 4913 & 2nd 1000 & - \\
\hline Occur_Unaccusative-V & 8 & 9 & 728 & 2nd 1000 & B2 \\
\hline Surprise_Psych-V & 9 & 2 & 684 & 1st 1000 & B1 \\
\hline Arrive_Unaccusative-V & 10 & 7 & 574 & 1st 1000 & A2 \\
\hline Disaapoint_Psych-V & 11 & 4 & 1973 & 2nd 1000 & B1 \\
\hline
\end{tabular}


The significant difference between the participants' performances on active and passive constructions of psych verbs, the participants', though nonsignificant, outperformance on unaccusative verbs as well as the accuracy on unaccusative verbs varying based on individual verbs and constructions imply that processing passivization cannot be the only effective factor determining the acquisition of psych and unaccusative verb constructions. Specifically, cross-linguistic factors and L1 interference can be some possible sources of the challenges faced by this sample group as indicated by Montrul (2001) who found that the crosslinguistic difference in transitivity between English and Turkish was responsible for Turkish learners' ungrammatical use of psych verbs because these learners used active psych-verb form where the Experiencer is the subject (e.g., *The hunter frightened).

\section{Conclusion}

The processability account anticipates that learners will make more underpassivization errors than overpassivization errors since passivization entails more processing. In a scenario where processability plays a role in the acquisition of English as an L2, passive constructions requiring more processing will be more difficult to acquire as compared to active constructions. As a result, L2 learners of English can potentially make more errors with passive constructions, favor active constructions over passive constructions, and even wrongly accept or use active constructions in the context where passives are necessary. In order to investigate these points, a set of research questions has been asked and answered.

Firstly, the results indicated that ELT students did not significantly performed more accurately on psych verbs or unaccusative verbs. The second point handled was whether the performances on psych and unaccusative verbs differ across the accuracy levels in GJT. The results showed that as the total level of accuracy in GJT increased, the level of accuracy with psych verbs and unaccusative verbs increased, too. They also indicated significant differences between the unaccusative verb scores of low and high accurate, and medium and high accurate participants while the difference is not significant between the scores of low and medium accurate participants. As for psych verbs, the results revealed significant differences between the psych verb scores of low and medium accurate, low and high accurate, and medium and high accurate participants. Thirdly, the comparison between the performances of the lowaccurate participants for psych verbs and unaccusative verbs indicated that unaccusative verb ranks were not statistically significantly higher than psych 
verb ranks. The same result is also valid for the medium-accurate and highaccurate participants. Fourthly, when the familiarity with psych and unaccusative verbs was investigated, the results indicated that ELT students were not more familiar with any verb type. Also, the familiarity ranks of two verbs did not also match up with the accuracy ranks of the same verbs in GJT. The participants' degree of familiarity with and accuracy level for two verbs do not correlate with each other at any significant level. Lastly, the study compared the participants' degree of accuracy for two types of verb constructions (i.e., passive and active), the results indicated that active construction ranks were statistically significantly different than passive construction ranks for each verb. All in all, the results suggested that beyond processability, such factors as L1 interference and word frequencies in English (Table 19) seem to impact the acquisition process.

\section{References}

Browne, C., Culligan, B., \& Phillips, J. (2013). The New General Service List. Retrieved from: http://www.newgeneralservicelist.org

Hahn, Hye-ryeong, (2011). Korean EFL learners' underpassivization and overpassivization: Psych verbs and unaccusatives. Foreign Language Education Research, 14, 54-76.

Kawaguchi, S. (2013). The relationship between lexical and syntactic development in English as a second language (pp. 92-106). In A. F. Mattsson \& C. Norrby (Eds.), Language acquisition and use in multilingual contexts: Theory and practice. Media-Tryck, Lund University.

Kurtoğlu, Ö. (2010). (Over)passivization errors of Turkish learners of English as a foreign language. Journal of Linguistics and Literature, 7(1), 29-53.

Kurtoğlu, Ö. (2006). A study on the passivisation errors of Turkish learners of English as a foreign language (Master's Thesis). Retrieved from Council of Higher Education Thesis Center (205789) https://tez.yok.gov.tr/UlusalTezMerkezi/tezSorguSonucYeni.jsp

Levin, B. (1993). English verb classes: A preliminary investigation. University of Chicago Press.

Montrul, S. (2001). First-language-constrained variability in the second-language acquisition of argument-structure-changing morphology with causative verbs. Second Language Research, 17(2), 144-194.

Nation, I. S. P. (2012). The BNC/COCA word family lists. Retrieved on September, 2018 from: https://www.victoria.ac.nz/lals/about/staff/paul-nation\#vocab-lists

Pienemann, M. (2005). An introduction to processiblity theory. In M. Pienemann (Ed.), Crosslinguistic aspects of processibilty theory (pp. 1-60). John Benjamins.

Pienemann, M., D Biase, B., \& Kawaguchi, S. (2005). Extending processiblity theory. In M. Pienemann (Ed.), Cross-linguistic aspects of processiblity theory (pp. 199-251). John Benjamins.

The English Vocabulary Profile (n.d.). Retrieved from: http://www.englishprofile.org/ 


\section{Appendices}

Appendix A

\section{Grammaticality Judgement Task (GJT) - Hahn (2011)}

Participant Name:

Year of Study : ( 1st ) ( 2nd ) ( 3rd ) ( 4th )

Gender : ( ) Female ( ) Male

INSTRUCTION: This study is conducted as a preliminary study for a $\mathrm{PhD}$ dissertation to investigate if the acquisition of specific constructions is affected by processing complexity of passivization. Please put a mark next to the sentence if you think that the test sentence is Grammatical (Correct) or Ungrammatical (Incorrect). Make your decisions only once, and do not turn back and correct your original answers after a second thought. Thank you very much for your cooperation and contribution.

\section{Certificate of Consent}

I have been invited to participate in this research about acquisition of specific constructions in English. I have read the related details above and consent voluntarily to be a par-

Date: ..../ ..../ .......

Signature: ticipant in this study.

\begin{tabular}{|c|c|c|}
\hline \multirow[b]{2}{*}{ Example: 1) The dog eating the meat. } & \multicolumn{2}{|c|}{ CORRECT INCORRECT } \\
\hline & & $\mathrm{x}$ \\
\hline Example: 2) The dog was eating the meat. & $\mathbf{x}$ & \\
\hline \multicolumn{3}{|l|}{ 3) The woman surprised to hear the loud noise. } \\
\hline \multicolumn{3}{|l|}{ 4) Several fires occurred in Seoul last year. } \\
\hline \multicolumn{3}{|l|}{ 5) This is the company that he likes to work. } \\
\hline \multicolumn{3}{|l|}{ 6) Jane told us that she was going to church. } \\
\hline \multicolumn{3}{|l|}{ 7) The boy fell into the swimming pool. } \\
\hline \multicolumn{3}{|l|}{ 8) The little girl was frightened, so she called the police. } \\
\hline \multicolumn{3}{|l|}{ 9) Her mother was died of cancer 5 years ago. } \\
\hline \multicolumn{3}{|l|}{ 10) The boy who finished all the assignments were so tired. } \\
\hline \multicolumn{3}{|l|}{ 11) The woman frustrated because she could not find help. } \\
\hline \multicolumn{3}{|l|}{ 12) The doctor asked him if he feels okay. } \\
\hline \multicolumn{3}{|l|}{ 13) He was embarrassed because he could not speak English. } \\
\hline \multicolumn{3}{|l|}{ 14) This is the topic that we want to talk about. } \\
\hline \multicolumn{3}{|l|}{ 15) The thief disappeared into the dark. } \\
\hline \multicolumn{3}{|l|}{ 16) All the people shocked to hear the news. } \\
\hline \multicolumn{3}{|l|}{ 17) Mr. Jones asked me what the problem was. } \\
\hline \multicolumn{3}{|l|}{ 18) Several storms were occurred in Seattle last year. } \\
\hline \multicolumn{3}{|l|}{ 19) The girl was disappointed when she found her grade. } \\
\hline \multicolumn{3}{|l|}{ 20) Your package was arrived a few hours ago. } \\
\hline \multicolumn{3}{|l|}{ 21) The hikers were surprised to see a big bear. } \\
\hline \multicolumn{3}{|l|}{ 22) Mary told her father that she has a fever. } \\
\hline 23) The people were frustrated because they lost all the money. & & \\
\hline
\end{tabular}


24) I asked him what kind of movies does he like.

25) A terrible accident happened last night.

26) The teacher embarrassed because she made a mistake.

27) The girl was disappeared into the forest.

28) The little boy who passed all the subjects was very proud.

29) The cat frightened when it saw a big dog.

30) Their parents died of cancer when they were young.

31) The boy disappointed because he got a bad grade.

32) People who have a lot of friends do not have time to watch TV.

33) The cup was fallen from the table

34) A letter from her mom arrived two days ago.

35) Everyone was shocked to hear the news.

36) The people in the room didn't know what was the problem.

37) So many things were happened to her last week.

38) People who have only one child wants to have more children.

Appendix B

\section{Word Familiarity Rating Task (WFRT) - Hahn (2011)}

INSTRUCTION: Please mark the degree of your familiarity with the individual words on a 4-point Likert scale:

(1) $=$ Very Familiar

(2) $=$ A Bit Familiar

(3) $=$ Quite Familiar

(4) $=$ Very Familiar

\begin{tabular}{|c|c|c|c|c|}
\hline & Very Unfamiliar & A Bit Familiar & $\begin{array}{c}(\mathbf{1}) \\
\text { Quite Familiar }\end{array}$ & $\begin{array}{c}(\mathbf{4}) \\
\text { Very Familiar }\end{array}$ \\
\hline Example: eat & & & & \\
\hline surprise & & & \\
\hline happen & & & \\
\hline arrive & & & \\
\hline disappear & & & \\
\hline shock & & & \\
\hline die & & & \\
\hline disappoint & & & \\
\hline occur & & & \\
\hline embarrass & & & \\
\hline fall & & & \\
\hline frighten & & & \\
\hline frustrate & & & \\
\hline
\end{tabular}


Appendix C

Accuracy for the structures used as distracters in GJT:

Number \& rate of the participants accurately answering

\begin{tabular}{|c|c|c|c|c|c|}
\hline & & Items & M & $\begin{array}{c}N \\
(33)\end{array}$ & [\%] \\
\hline Item 14 & (G) & Geography is the subject that Joseph wants to take. & .969 & 32 & 97 \\
\hline Item 28 & (G) & $\begin{array}{l}\text { The little boy who passed all the subjects was so } \\
\text { proud. }\end{array}$ & .969 & 32 & 97 \\
\hline Item 32 & (G) & $\begin{array}{l}\text { Students who do not pass the math exam must take } \\
\text { math again. }\end{array}$ & .939 & 31 & 93.9 \\
\hline Item 17 & (G) & Mrs. Jones asked me what the problem was. & .909 & 30 & 90.9 \\
\hline Item 6 & (G) & Jane told us that she was going to church. & .727 & 24 & 72.7 \\
\hline Item 10 & (UNG) & $\begin{array}{l}\text { The young woman who finished all the assignments } \\
\text { were so tired. }\end{array}$ & .727 & 24 & 72.7 \\
\hline Item 38 & (UNG) & $\begin{array}{l}\text { Students who does not want to take geography can } \\
\text { take history. }\end{array}$ & .696 & 23 & 69.7 \\
\hline Item 24 & (UNG) & I asked what kind of movies does he like. & .636 & 21 & 63.6 \\
\hline Item 36 & (UNG) & $\begin{array}{l}\text { The people in the room didn't know what was the } \\
\text { problem. }\end{array}$ & .575 & 19 & 57.6 \\
\hline Item 22 & (UNG) & Mary told her father that she has a fever. & .484 & 16 & 48.5 \\
\hline Item 5 & (UNG) & $\begin{array}{l}\text { A café is a small restaurant that people can get } \\
\text { a light meal. }\end{array}$ & .454 & 15 & 45.5 \\
\hline Item 12 & (UNG) & The doctor asked him if he feels okay. & .454 & 15 & 45.5 \\
\hline
\end{tabular}

$\mathrm{G}=$ Grammatical, $\mathrm{UNG}=$ Ungrammatical $($ Min. $=0 ;$ Max. $=1)$

Seray Tanyer, Samet Deniz

Der Erwerb von psychologischen und unakkusativen Verben durch türkische EFL-Studenten: eine Replikationsstudie zur Unterpassivierung und Überpassivierung

Zusammenfassung

Die Komplexität des Transformierbarkeit legt die Vermutung nahe, dass Lernende mehr Fehler hinsichtlich der Unterpassivierung als Überpassivierung begehen werden, weil die Passivierung einen höheren Aufwand an Transformation erfordert. Obwohl eine Studie zu psychologischen und einigen unakkusativen Verben deren Erwerb durch türkische Fremdsprachenlernende untersuchte, wurde bisher in keiner Arbeit der Erwerb der beiden genannten Verbgruppen durch Lernende unter dem Gesichtspunkt der Transformation einzeln analysiert. In diesem Zusammenhang ist die vorliegende Studie darauf abgezielt, zu untersuchen, ob die Komplexität der Passivtransformation den Erwerb von psychologischen und 
unakkusativen Verben beeinflusst. Außerdem wird die Frage behandelt, ob das allgemeine Genauigkeitsniveau in Grammaticality Judgement Task (GJT) und der Grad der Vertrautheit mit Zielverben mit dem Genauigkeitsniveau in Bezug auf die einzelnen psychologischen und unakkusativen Verben zusammenhängen. 33 Universitätsstudenten im Grundstudium nahmen an einem GJT und Word Familiarity Rating Task (WFRT) teil. Der GJT umfasste insgesamt 38 Punkte, und zwar 12 Sätze mit psychologischen Verben, 12 Sätze mit unakkusativen Verben, 12 Sätze mit Distraktoren und 2 Beispielsätze. Der WFRT war ein Fragebogen zur Vertrautheit mit 6 psychologischen und 6 unakkusativen Verben. Zur Datenauswertung wurden eine Reihe von nichtparametrischen Tests sowie deskriptive Statistiken verwendet. Die Ergebnisse machten deutlich, dass die Lernenden mit unakkusativen Verben genauer als mit psychologischen umgehen konnten. Sie begingen mehrere Unterpassivierungsfehler, indem sie ungrammatische Aktivkonstruktionen mit psychologischen Verben zuließen. Ihre Leistungen in Bezug auf die psychologischen und unakkusativen Verben zeigten Parallelen zu ihrem allgemeinen Genauigkeitsniveau in GJT, während ihr Grad der Vertrautheit mit und Genauigkeitsniveau von zwei Verben nicht miteinander korrelierten. Die Ergebnisse deuten darauf hin, dass Faktoren wie Transformierbarkeit und muttersprachlicher Transfer den Erwerb zu beeinflussen vermögen.

Schlüsselwörter: Fremdsprachenerwerb; psychologische Verben; unakkusative Verben; Unterpassivierung; Überpassivierung 
